\title{
Hematuria y fracaso renal agudo como debut de amiloidosis vesical secundaria. Presentación de un nuevo caso y revisión de la literatura
}

\author{
I. Gómez García, F. González Chamorro, E. Fernández Fernández, A. Palacio España,
}

R. Molina Burgos, E. Álvarez*, S. Conde Someso

Servicio de Urología y Servicio de Anatomía Patológica*. Hospital San Rafael. Madrid.

Actas Urol Esp 2005; 29 (6): 603-606

\section{RESUMEN}

HEMATURIA Y FRACASO RENAL AGUDO COMO DEBUT DE AMILOIDOSIS VESICAL SECUNDARIA. PRESENTACIÓN DE UN NUEVO CASO Y REVISIÓN DE LA LITERATURA

La amiloidosis vesical primaria es una patología infrecuente, no existiendo en el mundo más de 150 casos publicados, siendo aun más excepcional la amiloidosis vesical secundaria estando descritos alrededor de 25 casos. La amiloidosis vesical secundaria se asocia en la mayor parte de los pacientes a artritis reumatoide de larga evolución. El diagnostico clínico es difícil, siendo necesario el diagnóstico diferencial con los tumores vesicales. El estudio patológico e inmunohistoquímico, confirma el diagnóstico. Presentamos el caso de una paciente que debuto con hematuria franca, inestabilidad hemodinámica e insuficiencia renal, que requirió tratamiento combinado, médico y quirúrgico para la resolución de su cuadro.

Palabras clave: Amiloidosis Vesical. Pseudotumor vesical.

\section{ABSTRACT}

HEMATURIA AND SHARP RENAL FAILURE AS DEBUT OF SECONDARY BLADDER AMILOIDOSIS. PRESENTATION OF A NEW CASE AND REVISION OF THE LITERATURE

The primary bladder amiloidosis is an uncommon pathology, not existing in the world more than 150 published cases, being even more exceptional the secondary bladder amiloidosis being described around 25 cases. The secondary bladder amiloidosis associates in most from the patients to arthritis reumatoide of long evolution. He diagnoses clinical it is difficult, being necessary the differential diagnosis with the bladder tumour. The pathological study and inmunohistoquímics, confirm the diagnosis. We present the case of a patient that I debut with frank hematuria, hemodynamic uncertainty and renal inadequacy that it required combined treatment, doctor and surgical for the resolution of their square.

Keywords: Bladder Amiloidosis. Bladder Pseudotumor.

L a Amiloidosis es una enfermedad que se caracAeriza por el deposito de material hialino proteico extracelular que se tiñe con rojo congo. Existe diversas clasificaciones para la amiloidosis, sistémica (primaria o secundaria), familiar, y senil.

La Amiloidosis vesical secundaria (AVS) tiene un carácter excepcional, estando en la mayoría de los casos asociada a enfermedades autoinmunes como la artritis reumatoide y la espondilitis anquilopoyética.

\section{CASO CLINICO}

Mujer de 69 años con antecedentes personales de insuficiencia renal crónica (IRC) no filiada, artritis reumatoide (AR)de 20 años de evolución, en tratamiento crónico con corticoides. La paciente inicia un cuadro súbito de hematuria total anemizante, compromiso hemodinámico, acompañado de deterioro importante de la función renal (creatinina 6,9); tras cirugía ortésica de rodilla. La ecografía urológica los riñones son normales, sin alte- 
raciones en parénquima ni en sistema colector; se objetiva gran coágulo vesical.

Tras fracaso de manejo conservador con suero lavador, la enferma presenta desestabilización hemodinámica realizándose exploración endoscópica siendo imposible la extracción de coágulo; dada la situación se decide cirugía abierta, apertura vesical, extracción de coagulo, apreciándose mucosa vesical delustrada con sangrado en sábana, sin apreciarse lesiones vesicales macroscópicas. Se toma biopsias aleatorias de mucosa vesical siendo informadas como Amiloidosis vesical con afectación extensa de vasos (Figs. 1, 2, 3). Se procede al tratamiento con corticoides en perfusión y colchicina. La paciente es dada de alta sin hematuria y mejoría de la función renal (creatinina 2,3).

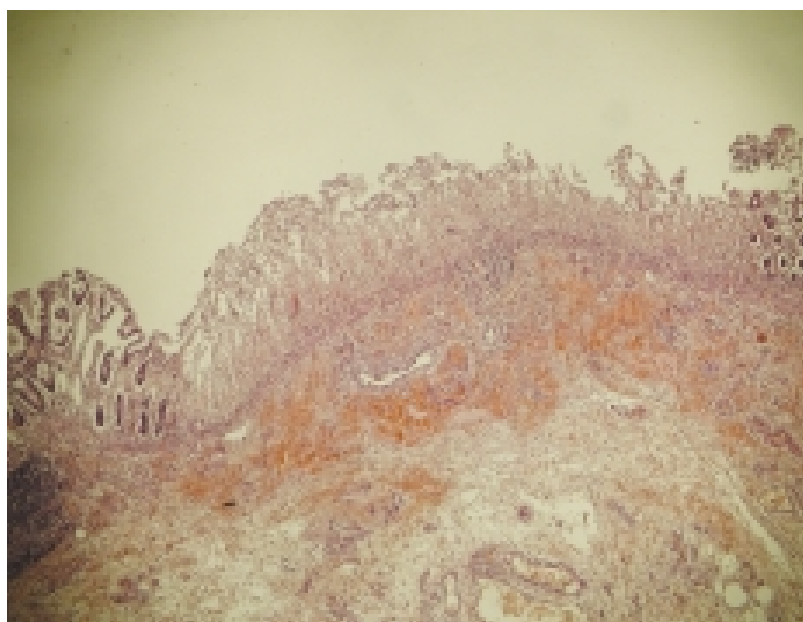

FIGURA 1. Urotelio intenso componente vascular y hemorrá gico.

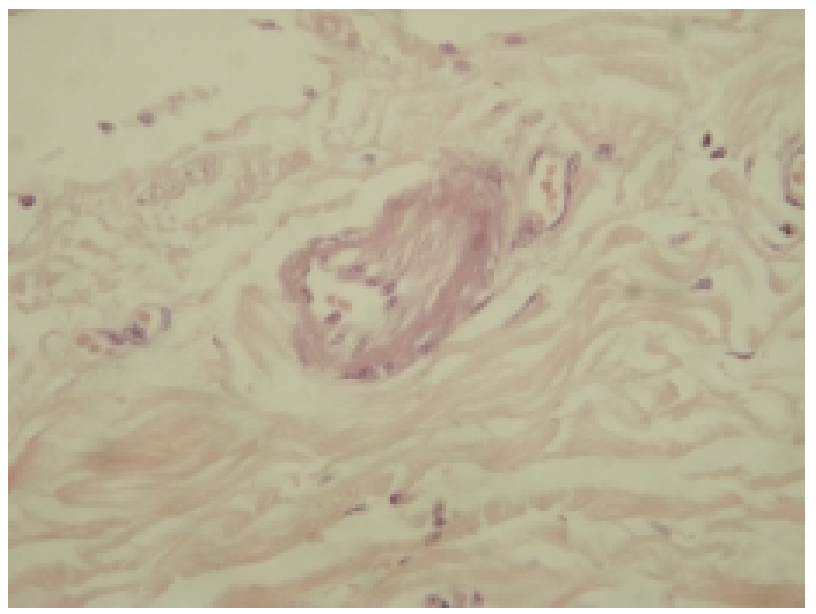

\section{DISCUSIÓN}

La Amiloidosis fue descrita en 1842 por Rokitansky, siendo Virchow en 1853 quien le otorgo el nombre debido a su similitud con las características tintoriales del almidón ${ }^{1}$. La primera descripción de la Amiloidosis vesical (AV) fue por Solomin en 1897. Bender y Nelly ${ }^{2}$ en 1969 describen el primer caso de Amiloidosis Vesical Secundaria (AVS). La serie más amplia de AVS, con cinco casos, fue publicada por Nurmi et al. ${ }^{3}$, no existiendo mas de 25 casos publicados en la literatura mundial. En España hemos encontrado referencias de 5 casos $^{1,4-6}$ de AVS.

La amiloidosis, suele tener la misma incidencia en ambos sexos, siendo la afectación en el varón mas temprana; mientras que la afectación vesical es mas frecuente en la mujer.

La amiloidosis, es un grupo de enfermedades que se caracteriza por el deposito extracelular de proteínas de estructura fibrilar denominado amieloide. El amieloide se deposita en una o varios órganos, produciendo distinta sintomatología dependiendo de la cantidad y del órgano afecto por el amieloide ${ }^{1}$. La Amiloidosis se puede dividir en dos grandes grupos la sistémicas y las localizadas. La amiloidosis sistémica suele ser secundaria a enfermedades sistémicas como la artritis reumatoide, infecciones crónicas, neoplasias, espondilitis anquilopoyética, fiebre mediterránea familiar, tuberculosis, osteomielitis.... La amiloidosis sistémica se desarrolla tras un estimulo inflamatorio crónico de años de evolución ${ }^{7}$.

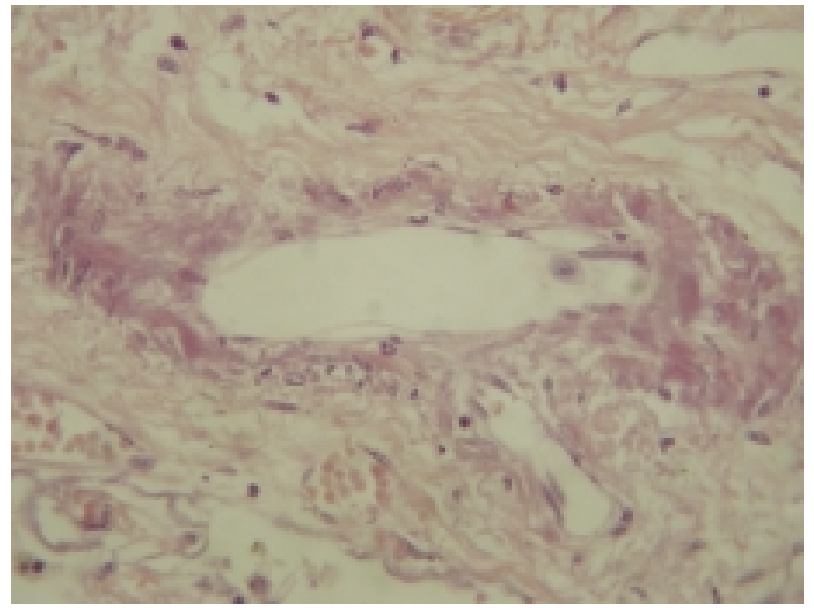

FIGURAS 2 y 3. Hematosilina eosina, detalle de vaso sanguineo suburotelial con infiltrado inflamatorio y destructuramiento de su pared. 
La artritis reumatoide es la causa más frecuente de amiloidosis vesical secundaria ${ }^{1,4-6,8-11}$.

La sintomatología de la Amiloidosis sistémica, viene determinada por los órganos afectados.

La hematuria anemizante, incoercible, y refractarias al tratamiento ${ }^{1,3,5-8,10,11}$, es la manifestación más usual de la AVS. La hematuria es el síntoma princeps en AVS debido al carácter difuso de la afectación; mientras es inusual (no más de un $4,7 \%$ ) en paciente amiloidosis vesical primaria (AVP) ${ }^{10}$. Un $20 \%$ de los pacientes suele presentar manifestaciones cutáneas asociadas como púrpura, pápulas y nódulos. La afectación del tracto gastrointestinal es frecuente, siendo excepcional la presencia de sintomas digestivos.

En 1944 Corbitt et al. describen por primera vez la imagen cistoscópica de la amiloidosis, como un área enrojecida mínimamente sobreelevada que asemeja a la cistopatía intersticial. Otros signos visualizables en la cistoscopia suele apreciarse mucosa hiperémica, eritematosa, y sangrante a la distensión vesical ${ }^{4}$; también se pueden apreciar áreas inflamatorias, ulceradas, lesiones excrementes y placas blanco amarillentas que corresponden a depósitos de material amieloide en la pared ${ }^{4,5,11,12}$.

El diagnóstico de confirmación lo da el informe patológico mediante la demostración del deposito de amieloide con la tinción de rojo congo con luz polarizada birrefringente. La AVP la afectación suele ser focal y excrecente, simulando a un pseudotumor, mientras que en la AVS suele existir una afectación difusa de toda la vejiga simulando a una cistitis hemorrágica ${ }^{4}$. La afectación en la AVP, se caracteriza por deposito en la pared de los vasos de la submucosa y en la muscular; mientras que en la AVS, existe mayor afectación en los vasos suburoteliales, que en los vasos de la capa muscular ${ }^{8}$. Esta localización del amieloide implica una mayor sangrado en las AVS que en las AVP. Desde el punto de vista microscópico el amiloide se tiñe de rosa con la hematoxilina-eosina, presentando metacromasia con violeta de metilo, la exposición con luz polarizada birrefringente de la tinción de rojo congo produce un color verde manzana característico. La amiloidosis primaria el amieloide esta constituido por fragmentos móviles de cadena ligera de inmunoglobulina (AL), mientras que en las secundarias esta formado por fibrillas de proteína A
(AA); en ambas Amiloidosis existe un componente común denominado unidad pentagonal o componente "P". La diferenciación entre la AVP y la AVS debe realizarse mediante técnicas de inmunohistoquímica (inmunoperoxidasa) ${ }^{5}$ y el empleo de anticuerpos monoclonales (Acm Ab-1) ${ }^{13}$. Los depósitos de amieloide se pueden localizar en cualquier parte del cuerpo, siendo el riñón el órgano del tracto urinario mas frecuentemente afectado y el glomérulo el área mas afecta. Se ha descrito afectación de todos los órganos del aparato genitourinario: riñón, uréter, vejiga, próstata, pene, testículo, y vesículas seminales ${ }^{2,4,7,8,14,15}$.

Dada la alta incidencia de afectación asintomática del aparato digestivo, muchos autores abogan por la biopsia rectal, o de la grasa abdominal en los pacientes con sospecha de amiloidosis sistémica ${ }^{4,16}$.

$\mathrm{El}$ diagnóstico diferencial de la AV debe de ser en primer lugar con los tumores vesicales, seguido de cistopatía glandular y quística, endometriosis, malocoplaquia, tuberculosis vesical ${ }^{4,11}$.

Respecto al tratamiento, en el caso de las AVS es primordial el tratamiento y control de la enfermedad de base. Las medidas conservadoras basadas en el lavado vesical con sustancias procoagulantes se deben instaurar lo más precozmente. Se ha utilizado diverso arsenal terapéutico abarcando desde corticoides, dimetilsulfoxido y colchicina, instilaciones con solución de alumina ${ }^{3,6,16,17}$.Si con medidas de manejo básico, no se puede controlar el sangrado o produce uropatía hay que proceder a medidas más agresivas como la fulguración transuretral, cistotomía evacuadota ${ }^{4}$; y en ocasiones llegando a recurrir a la ligadura de las arterias hipogástrica y cistectomía ${ }^{3,4,6}$.

\section{CONCLUSIONES}

La AVS es en una entidad infrecuente no habiéndose descrito más de 25 casos en el mundo. Se observa en pacientes con patologías crónicas en especial en aquellos con artritis reumatoide de larga evolución. El síntoma fundamental es la hematuria franca y anemizante. El diagnostico es patológico, mediante la demostración del deposito de amieloide AA. Existen diversas opciones terapéuticas, pero en la mayoría de los casos, el difícil diagnostico diferencial con tumor vesical y el compromiso hemodinámico, condiciona una actitud quirúrgica. 


\section{REFERENCIAS}

1. Begara Morillas F, Silmi Moyano A, Espinosa Fernández B, et al. Amiloidosis vesical en un paciente con sospecha de tumor vesical. Arch Esp Urol 1994;47(2):176-179.

2. Bender LM; Nelly CH. Secondary amyloidosis of the blazer: a case report. J Urol 1969;102:60-62.

3. Nurmi MJ; Walls J. Secondary amyloidosis of the bladder: a cause of massive hematuria. J Urol 1997;138:44-45.

4. Bielsa O, Romero JA, Alcaraz A. Amiloidosis vesical secundaria. Una rara causa de hematuria. Actas Urol Esp 1990 Jan-Feb;14(1):76-77.

5. Palmero Martí JL, Budía Alba A, Arladis Guzman S, et al. Amiloidosis vesical secundaria. Actas Urol Esp 2004;28(3) 238-242.

6. Caballer Gine JM, Borrat Font L, Martí Picas L, et al. Amiloidosis vesical: Presentación de dos casos. Actas Urol Esp 2000;24(5):413-415.

7. Días R, Fernándes M, Patel RC, et al. Amyloidosis of renal pelvis and urinary bladder. Urology 1979;14(4):401-404.

8. Tesedo Cubero J, Ristol RM, Fernández Zuazu J. Hematuria masiva y perforación vesical, complicación de una amiloidosis sistémica. Arch Esp Urol 1991;44:862-864.

9. Martínez Vázquez JM. Amiloidosis. Farreras Rozman. Ed. Doyma. 199.

10. Jaka JP et al. Afectación vesical en la amiloidosis sistémica. Arch Esp Urol 1988;41:325.
11. Ahmad E, Johansson SL, Magnus Fall: Blue spotted Bladder A manifestation of bladder amyloidosis. Scand J Urol Nephrol 1986;20:145-147.

12. Vicente J, Algaba F. Semiología diagnóstica endovesical: amiloidosis vesical. Pulso Ediciones S.A.1998;105-113.

13. Linke RP. Identification of AA-Type Amyloid in Tissue sections using monoclonal antibodies. In Peeters H, ed. Protides Biol Fluids Oxford. Pergamon Press 1983;31:835-838.

14. Trívez Boned MA, Blas Marín M, García García MA, et al. Amiloidosis localizada de la uretra. Actas Urol Esp 2002;26(1):46-49.

15. Herranz Fernández LM*, Arellano Gañán R, Syonghyun Nam CHA,et al. Amiloidosis localizada de vesículas seminales. Actas Urol Esp 2003;27(10):825-828.

16. McCammon KA, Lentzer AN, Moriarty RP, et al. Intravesical Dimethyl Sulfoxide for primary amyloidosis of the bladder. Urology 1998;52:1136-1138.

17. Sanz JP, Arrinda AM, Mendibil J. Afectación vesical en la amiloidosis sistémica. Arch Esp Urol 1988;41(4):325-328.

Dr. I. Gómez García

María Tubau, no 15; Ptal. 3 - 1ํㅡ

28050 Madrid

(Trabajo recibido el 4 octubre 2004) 